Voix et Images

volxetimages

\title{
Maria Chapdelaine : le tapuscrit manquant
}

\section{Gilles Thérien}

Volume 9, numéro 1, automne 1983

Guy Dufresne

URI : https://id.erudit.org/iderudit/200432ar

DOI : https://doi.org/10.7202/200432ar

Aller au sommaire du numéro

Éditeur(s)

Université du Québec à Montréal

ISSN

0318-9201 (imprimé)

1705-933X (numérique)

Découvrir la revue

Citer ce compte rendu

Thérien, G. (1983). Compte rendu de [Maria Chapdelaine : le tapuscrit manquant]. Voix et Images, 9(1), 171-173. https://doi.org/10.7202/200432ar d'utilisation que vous pouvez consulter en ligne.

https://apropos.erudit.org/fr/usagers/politique-dutilisation/ 
CINÉMA

Maria Chapdelaine : le tapuscrit manquant

par Gilles Thérien, Université du Québec à Montréal

Depuis deux livraisons, Voix et Images a vécu la querelle de l'édition critique de Maria Chapdelaine. Tout portait à croire que l'incident était clos jusqu'à ce que l'auteur de cette chronique fasse son devoir national en allant voir ce beau grand film qui n'a pas encore réussi à «faire» le centre-ville de Montréal. Il demeure modestement à l'est de «la Main» et a élu domicile à l'ombre du, département d'études littéraires de l'UQAM dans l'espoir vraisemblable de voir affluer tous les spécialistes de la littérature et les cohortes d'étudiants conscrits par le nationalisme littéraire. Maria Chapdelaine de Gilles Carle qui signe le scénario avec Guy Fournier repose de façon dramatique tout le problème de l'édition critique car voici qu'il existe maintenant une nouvelle source d'information. On ne peut que reprocher à ces auteurs de n'avoir pas mis la communauté intellectuelle au courant de leur découverte d'un tapuscrit inconnu du roman de Louis Hémon. Selon toute apparence, on peut dire que ce tapuscrit est antérieur à ceux qui dorment actuellement dans les archives évoquées par la récente querelle. La forme romanesque y est plus pure, moins encombrée. Les événements ont l'avantage d'y être présentés clairement, dans un ordre linéaire et causal abandonné dans les versions ultérieures. Les personnages y sont plus schématiques : Maria est romantique, Eutrope niais au grand coeur, François muet d'amour, Lorenzo sûr de lui... La dernière version serait devenue plus complexe, plus fine, plus stylisée si on en croit le roman contre le film. Il faut certainement en faire remonter la responsabilité à ce tapuscrit manquant plutôt qu'à une savante manipulation narratologique qu'auraient créée deux scénaristes particulièrement futés. J'en veux aussi pour preuve l'absence de danse du ventre de Carole Laure qui aurait pu être imputée à l'unique imagination de Carle ou encore l'inexistence des habituelles blagues que l'on retrouve sous la plume de Fournier. Évidemment quelqu'un de mieux informé pourrait mettre en doute mes hypothèses et offrir une tout autre interprétation dans le prochain Voix et Images. Mais revenons au film.

En voyant Maria Chapdelaine, on ne peut s'empêcher de croire que le cinéma a comme principal effet de donner du mouvement, de la vie à ce qui 
n'en a pas. Le film est fait sans grande conviction, les comédiens traduisent ce sentiment volontairement ou non, tous sauf peut-être Claude Rich qui joue le curé avec un plaisir non feint. Les séquences se suivent avec toute la rationalité d'un bon documentaire selon un rythme qui ne parvient pas à s'établir de façon nette. Les événements sont aplatis, sans contenu idéologique, la vie défile en deux dimensions. Il ne lui manque que la profondeur. Les personnages sont réduits à des silhouettes, à des caricatures, à des clichés.

Les thèmes idéologiques ne manquent pourtant pas. Le personnage de Maria, dans le roman, est aux prises avec le destin sous la forme de la mort ou sous la forme de l'appel, de la vocation. Mais Maria n'est pas une jeune fille romantique indécise. C'est au contraire «une belle grosse fille, et vaillante avec ça». Elle a trois prétendants qui lui offrent trois univers différents. Elle en choisira un auquel elle ne pourra accéder et sera finalement obligée de décider entre la patrie dans la misère ou l'exil dans l'inconnu. Tous les sentiments sous-jacents à cette problématique ne sont-ils pas encore très modernes? Si les événements du film sont fidèles à ceux du roman, il manque une problématisation des personnages, une mise en perspective de Maria par rapport à la famille, au pays, à la religion. Le film ramène tout à l'anecdotique.

$\mathrm{Si}$, à ce titre, on compare, et la comparaison est inévitable, les Plouffe et Maria, il faut reconnaître que la différence repose sur le scénario. Celui des Plouffe a été enrichi, celui de Maria appauvri. Les Plouffe réussissait à monopoliser l'attention du spectateur sur le comportement individuel, familial et social de tous ses personnages, sur les divers types de discours tenus. Maria Chapdelaine se présente comme un tableau vivant, une nature morte avec automates : l'absence de drame éprouvé, senti, exprimé, l'impuissance d'une nature qui aurait pourtant dû toujours avoir le dernier mot, voilà ce que n'arrive pas à rendre ce film qui suinte l'ennui. Il serait tentant de rejeter la faute sur l'original et d'affirmer que c'est le roman luimême qui est ennuyeux.

Et pourtant, il n'en est rien. Ce roman que tous croient connaitre est d'une heureuse lecture. Bavard bien sûr si l'on considère la position du narrateur, il oppose continuellement la nature et le combat qu'elle exige à la vie intérieure, dans la maison mais aussi au-dedans de soi et les combats qui en découlent. Depuis sa parution, on a voulu en faire le champion du catholicisme ou de la colonisation. Il suffit d'y lire une point d'ironie pour y retrouver de multiples autres interprétations. C'est justement ce qui manque dans le film de Gilles Carle, une interprétation! La volonté de «respecter le roman», si elle a existé, est en fait le désir de faire un bon film de série B avec un roman populaire, - populaire pour qui? On croit aveuglément à la magie des images et à l'efficacité d'un déroulement narratif revu et corrigé selon les règles les plus simplistes avec la très noble préoccupation de ne pas 
«mêler» le spectateur. On sait ce que cela a donné avec Kamouraska : un film d'époque.

Les images du film sont très belles mais comme des cartes postales, plus album photographique de luxe qu'intrusion dans un univers inconnu où se nouent et dénouent les drames du quotidien. Cette photographie inspirée du «travelog» détruit l'impression de profondeur. Jamais la nature ne nous entoure sauf au moment où on accompagne le cheval qui va chercher le guérisseur. Subitement on a presque l'impression bienheureuse de la troisième dimension. Sinon, les paysages défilent et la distance comme le point de vue ne permettent pas de créer un champ visuel continu entre l'écran et le spectateur. Les mises en scène sont soigneusement composées pour entrer dans le champ de la caméra, créant l'impression de l'artificiel et du manque derrière la caméra. La beauté des images s'accorde si mal avec la nature «implacable» qu'on ne croit pas à son maléfisme. Elle n'a rien de repoussant, de détestable, de mortel, cette nature toujours bien cadrée, à distance suffisante pour être admirée. Les personnages non plus n'ont pas l'air d'en souffrir trop. La mort de François Paradis est nimbée d'esthétique, celle du bûcheron se fait dans les couleurs crues des troncs d'arbres sur fond de neige. On ne sent pas cette nature reculer devant l'effort des pionniers et l'arrachage des souches prend plus l'allure d'une compétition d'hommes forts.

Pour le spectateur québécois, ce film comporte des énigmes inutiles. Pourquoi Mancuso (François) parle-t-il avec la voix de Robert Gauthier, ou encore, version acceptable, pourquoi Gauthier a-t-il la voix et non le corps de l'emploi? Pourquoi entend-on chanter le «Minuit, chrétiens», par Yoland Guérard (le père Chapdelaine) quand on voit Paul Berval (le marchand général), dont la voix n'est pas désagréable, le chanter? Pourquoi ce subtil jeu des voix, n'est-ce pas un peu trop de magie? Pourquoi un curé français au lieu d'un bon Québécois taillé dans le paradigme du curé Labelle? Pourquoi la musique de Lewis Furey et non pas quelque chose d'un peu plus moulé sur le patrimoine musical québécois? On oserait presque demander pourquoi Carole Laure mais cette question est... En somme, si l'on voulait faire une histoire d'amour rétro de série B, pourquoi Maria Chapdelaine?

Des conflits avec la nature, avec la société, des combats intérieurs sont souvent difficiles à traduire en images mais en pensant à l'Arbre aux sabots d'Olmi ou à l'Ile nue de Shindo, on se prend à imaginer que ce ne sont pas les solutions qui manquent mais le talent. 